Article

\title{
Fit-for-Purpose Infrastructure Asset Management Framework for Water Utilities Facing High Uncertainties
}

\author{
Assela Pathirana ${ }^{1, *(\mathbb{D})}$, Mohanasundar Radhakrishnan ${ }^{1}\left(\mathbb{D}\right.$, Maaike Bevaart $^{2}$, Eric Voost $^{2}$, \\ Salameh Mahasneh ${ }^{3}$ and Hiba Abu Al Rob ${ }^{4}$ \\ 1 Flood Resilience Research Group, Department of Water Science and Engineering, IHE-Delft Institute for \\ Water Education, Westvest 7, 2611AX Delft, The Netherlands; mohanasundar@gmail.com \\ 2 Asset Management Department, Waternet, Korte Ouderkerkerdijk 7, 1096AC Amsterdam, The Netherlands; \\ maaike.bevaart@waternet.nl (M.B.); eric.voost@waternet.nl (E.V.) \\ 3 Water Authority of Jordan, Jaber Bin Hayyan St 5, Amman 11184, Jordan; salamehyw@gmail.com \\ 4 WASH Specialist, UNICEF Jordan CO, PO BOX 1551, Amman 11821, Jordan; habualrob@unicef.org \\ * Correspondence: assela@pathirana.net; Tel.: +31-(0)-15-215-1854
}

Received: 23 August 2018; Accepted: 25 November 2018; Published: 4 December 2018

\begin{abstract}
Traditional infrastructure asset management is about maintaining the status quo of service levels in a resource-restricted, sometimes risk-increasing environment. Infrastructure asset management (IAM) is effective in addressing resource-deprived situations and in maximizing the benefits of the utility in these contexts. This makes IAM a very appropriate and useful approach for developing countries. Hence, this paper focuses on developing a fit-for-purpose integrated asset management (IAM) framework that is suitable for situations where there are risks to assets, significant uncertainties, and resource deficits, and where improvements to the current service levels are needed. To be comprehensive in the application in these contexts, there is a need to supplement IAM with a new perspective-critical necessities, next to the risks to the status quo (current levels of service). This gap was evident during application of IAM principles to the drinking water system of Al-Mafraq, Jordan. It was overcome by framing questions on adaptation deficits and future needs that are to be answered together with risk matrix-based prioritization of asset management actions. The fit-for-purpose IAM framework comprising asset management, adaptation deficit, and future needs can ensure the continuity of service levels in emerging cities when supported through expert inputs and stakeholder consultations.
\end{abstract}

Keywords: asset management; urban water systems; risk-based decision making; adaptation deficits; adaptation gaps; secondary cities in the global south

\section{Introduction}

Asset management (AM) can be seen as a necessity that arose from the relative inability of traditional engineering to deal with resource-constrained situations. Infrastructure engineering (e.g., water supply, oil and gas, transportation, etc.) concepts and practices that were developed during times of plenty do not work well during times of resource deprivation [1-5]. The operation and maintenance practices were routine and affordable during the expansion of the oil and gas industry in the 1970s. However, these were not financially viable after the oil price crash that followed, and they were silently ignored or only selectively implemented, leading to disasters, such as the Piper Alpha oil platform explosion in the United Kingdom (UK) [6]. The findings from the landmark report on infrastructure in the United States of America (USA) [7], and the poor status of water infrastructure in Australia and New Zealand in the early 1990s, as well as the recent reports [8,9], reiterate the 
following: (i) operation and management (O\&M) practices that were developed during times of relatively good sector performance do not fit well for the hard times; and (ii) infrastructure asset management (IAM) was born out of necessity to guide organizations to spend the limited funds to minimize the risk to its service levels (SL). Also, according to the definition in the International Organization for Standardization (ISO) 55000 standard [10], asset management is about making intelligent choices to maintain the SL of infrastructure with limited resources and to respond to the unviable way of financing the O\&M practices of the past in a resource-restricted environment.

Infrastructure asset management is about maintaining the status quo of service levels in a resource-restricted, sometimes risk-increasing environment (e.g., climate risk) [11,12]. Therefore, IAM implicitly assumes that this status quo or the current service levels are acceptable. This is a reasonable assumption for many of the situations where infrastructure asset management was successfully applied to integrate asset management across multiple disciplines and across levels in sectors such as transportation [13-15], the oil and gas industry, and the urban water sector [1-5,16]. As the idea of IAM was co-developed by a number of different organizations in different countries (e.g., the UK, USA, Australia/New Zealand, Canada, and the Netherlands), there are a number of slightly different definitions that are in use. The international standard for IAM ISO 55000, which largely followed the developments in the UK, defines IAM as "the coordinated activity of an organization to realize value from assets" [10]. The United States Environment Protection Agency (EPA) defines it as "a process for maintaining a desired level of customer service at the best appropriate cost" [17]. Australia's Institute of Public Works Engineering Australasia (IPWEA)'s International Infrastructure Manual (IIMM) defines it as "to meet a required level of service, in the most cost-effective manner, through the management of assets for present and future customers" [18]. According to IHE-Delft Institute for Water Education (IHE-Delft), which offers postgraduate level courses on asset management since 2006, "asset management is the activity of 'mainstreaming' the rational and systematic resource allocation decision-making, for optimal use of limited resources" [19].

An important related practice to IAM is that of strategic planning (SP). Strategic planning is the process of identifying an organization's long-term goals and objectives and how best to achieve and sustain them. EPA's strategic planning for small water systems states that the idea of SP is to "plan today for an uncertain tomorrow" [20]. SP can address both known problems of tomorrow, as well as prepare for unknown issues that may arise in the future [20]. Obviously, SP and IAM are very much related concepts, but they are two distinctly different aspects of managing an asset system over time. SP provides the direction and boundaries within which AM should operate. On the other hand, AM provides a "reality check" for SP-as it is hard to develop a realistic future vision without a good understanding of current realities, such as frequencies of failure and consequence of failure, which are provided by a good IAM process.

Development of an IAM framework for a given system is often facilitated by a set of guiding questions. For example, the asset management framework of Waternet, the water cycle company of Amsterdam and surroundings, is based on five questions that focus on long-term service levels; performance and the current state of assets; criticality of assets; minimum life-cycle cost; and long-term funding strategy [16,21]. EPA's asset management 101 for small utility companies defines five questions that cover IAM and SP concepts [17]. At IHE-Delft, AM comprises four questions, separate from those related to SP: (i) What we have?-Asset inventory; (ii) What is the condition of assets?-Condition assessment; (iii) What is the importance of assets?-Identifying assets important for service provision and continuity of services; (iv) What to fix first?-Risk-based prioritization of O\&M and renewal [19,22-24]. These questions were synthesized based on the needs that are prevalent in the asset management sector [25]. A closer examination of IAM success stories and applications reveals that almost all of them are from the developed country context where the aforesaid maintaining of the existing service levels was the primary challenge [26-28]. IAM is effective in addressing resource-deprived situations and in maximizing the benefits of an infrastructure system. This makes IAM a very appropriate and useful approach for developing countries, where the resource-deprived 
situation holds true. But the developed country contexts are challenged not only by the effort of maintaining the current SL but by an often acute need to upgrade the current service levels. Hence, the implicit assumption that IAM's most important goal is to minimize the risks to the current service levels has to be challenged.

A contextual fit-for-purpose infrastructure asset management framework is necessary to address the multiple challenges of (a) minimizing the risk of current service levels from deterioration due to internal causes like ageing systems, as well as external causes such as limited water resources, climate change impacts, and rapid population growth [29]; (b) addressing the critical shortfalls in the current service levels by system improvement [1,23]; and (c) prioritizing investments and measures of operation and maintenance [24]. Hence, this paper focuses on developing a fit-for-purpose IAM framework that is suitable for situations where there are risks to assets, significant uncertainties, and resource deficits, and where improvements to the current SL are needed. The focus area of the IAM application is Al-Mafraq, a host community for refugees from Syria, served by Yarmouk Company, which is in charge of water supply and wastewater management. Al Mafraq City is hosting one of the biggest refugee camps in the region, in addition to refugees living in hosting communities, which led to the doubling of the population in this resource-deprived arid governorate [30,31]. The performance of municipal services in Al-Mafraq is challenged by rapid urbanization, dwindling water resources, and a rapid surge and variability of refugee influx from Syria [30,32].

\section{Asset Management and Risk-Based Decision-Making in Water Utilities}

The inspiration to challenge the implicit assumption of IAM is from our experience of introducing infrastructure asset management methodology [16] to Yarmouk Company, a water utility serving four governorates in northern Jordan. The objective of tactical level asset management at water utilities is to identify an optimized set of interventions to maintain service levels in the long term. In order to do this, water utilities make use of the "five core management questions" of USEPA [17], which also forms the basis for the Common Framework for Capital Maintenance Planning (CFCMP) in the UK [33]. For example, Waternet applies the asset management process at three levels-system functioning, network functioning, and object functioning — to find suitable answers to five questions [21]:

1. What are the required long-term service levels? Additionally, in which environment must this service level be delivered?

2. What is the current state of the assets? What will be the future performance of the infrastructure system?

3. Which assets are critical for achieving the long-term service levels?

4. What are the best minimum lifecycle cost continuous improvement programs and operation and maintenance strategies?

5. What is the best long-term funding strategy?

Close examination of these questions shows that they cover important concerns of AM (questions 2, 3 and 4) and SP (questions 1 and 5). Waternet's set of questions misses the most basic (but essential and important) question of "What do we have?", which leads to the asset inventory. Waternet's framework implicitly assumes this. However, a review of various sets of IAM questions [10,17-19,21], despite their apparent differences, unfurls a framework to achieve two common objectives:

(a) Risk-based decision-making: the ability to systematically prioritize O\&M, renewal, and replacement activities considering the financial and other constraints in order to minimize risks to ensure expected SL (IAM objective);

(b) Preparation for future changes (both foreseen and unforeseen) including demand and supply changes, and financing (SP objective).

All activities associated with IAM, such as asset inventorying, condition assessment, and failure consequence analysis, can be seen as contributors to the central goal of risk-based decision-making. 


\section{Risk-Based Decision-Making}

The central component of most IAM frameworks and tools is the risk matrix that provides a "dashboard" for IAM decision-making. Risk matrices are widely promoted in risk management standards and reference books and are used in a number of different disciplines like disaster risk management, production management, defence applications, logistics, etc. [34]. A risk matrix formulated to assess water-quality-related risk [35] is shown in Figure 1. The green-coloured cell indicates low-risk and no further action is required, whereas the red cells indicate high-risk and actions have to be taken to reduce those. Risk matrices are both lauded and criticized for their appropriateness in decision-making [36,37]. According to Talbot [37], some of the advantages in using risk matrices are (i) robustness in decision-making; (ii) consistency in prioritizing risks; (iii) keeping the focus on high-priority risks; and (iv) presenting complex risk data in a concise visual fashion. However, risk matrices are blamed for poor resolution, errors in mistakenly assigning high qualitative ratings to smaller risks, suboptimal resource allocation, and ambiguity [36].

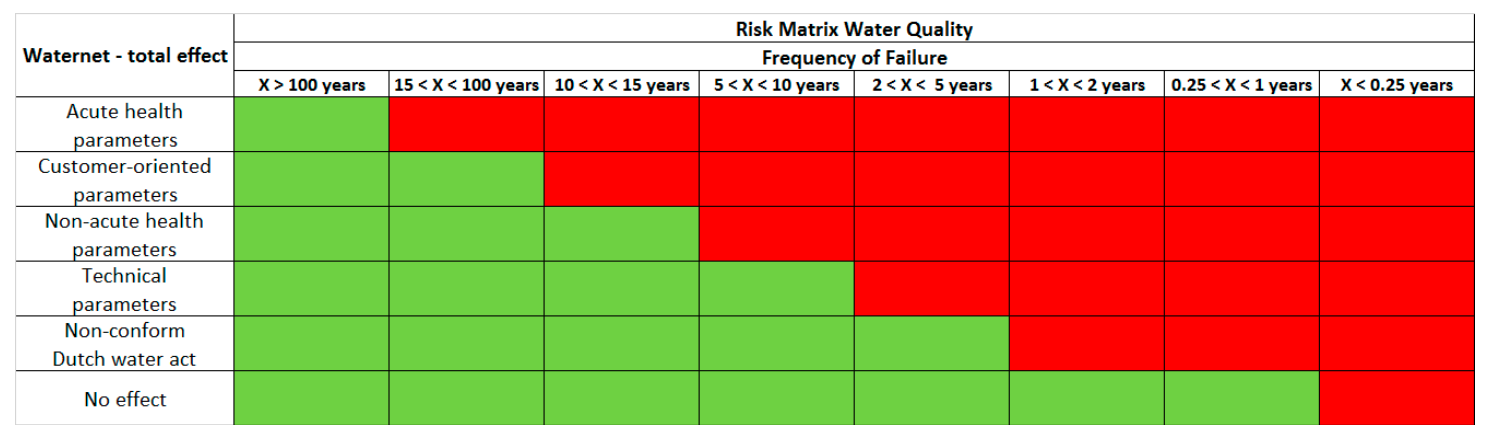

Figure 1. A risk matrix for water quality risk [35]. Each event can be plotted as a point in this matrix.

Alternatively, each point can represent an asset (then even = failure of that asset).

Understanding that risk can be defined as the product of probability and consequence of failure, this figure shows risk as increasing diagonally with increasing consequence and probability. A given high-probability low-consequence event (B in Figure 2) and a low-probability high-consequence event (A in Figure 2) can result in the same risk score (depicted by colours in Figure 1, but can be represented as a number too). However, in the IAM context, while it is true that the risk scores of A and B are the same, the actions that have to be taken to address them are completely different. This is illustrated in Figure 2. While the appropriate action to manage the risk of type B is close monitoring, that for $A$ is to follow a cost/benefit-based decision-making process, whose results may lead to a decision whether to operate to failure or renew / replace.

As stated above, it is the risk matrix that occupies the central place in an asset management system or a tool (e.g., asset management at Waternet Amsterdam, and the check-up program for small systems (CUPSS) asset management tool for small utilities by USEPA [38]). Asset management strategies differ for different combinations of failure frequencies and consequences of failure [39]. At the onset, the intention was to use the risk matrix approach to the drinking water supply system in Al-Mafraq to help prioritize investment actions. However, later in this paper, it is explained that the risk-based approach is only one, albeit an important, aspect of the process of prioritizing investment actions. 


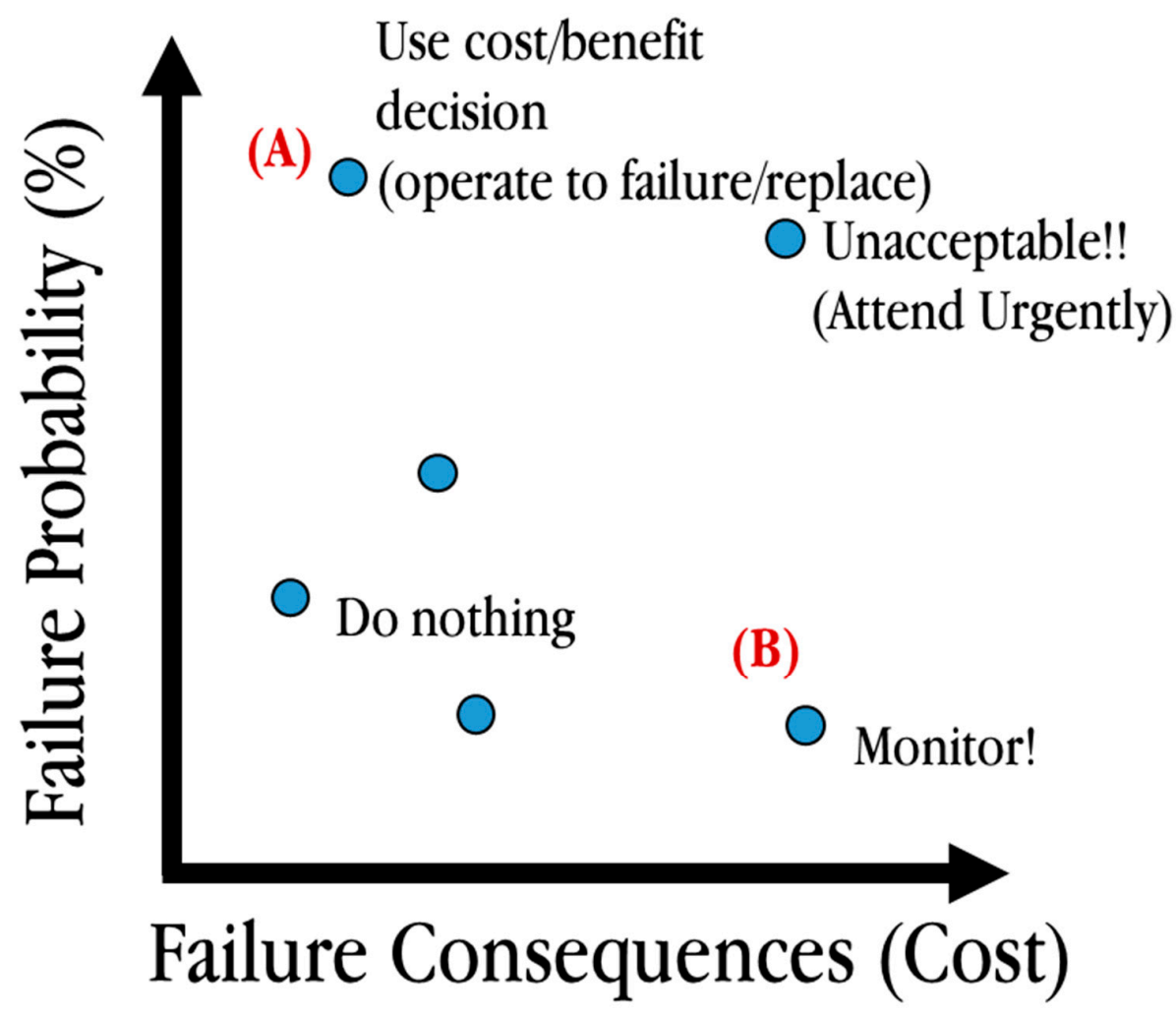

Figure 2. A risk matrix for infrastructure asset management (IAM). Typically, in IAM, risk matrices are populated with assets representing points (as opposed to events). While assets A and B may represent the same risk value, the actions that are warranted are markedly different. Asset A's risk is mostly contributed by high failure probability, not a consequence. In these cases, it is useful/appropriate to do cost-benefit analysis-type decision-making, i.e., to decide whether to replace now, later or after failure, based on the cost-benefit ratio and its evolution over time. In the case of asset $B$, the risk is largely due to higher failure consequences. Hence, asset B can benefit from a good monitoring scheme.

\section{Introducing IAM at Al-Mafraq/Jordan}

In May 2017, a three-day asset management training was organized in Amman for about 20 participants from the Jordanian Ministry of Water and Irrigation, Project Management Unit of the Ministry, United Nations High Commission for Refugees (UNHCR), United Nations International Children's Emergency Fund (UNICEF), and the three water utilities: Yarmouk, Miyahuna, and Aqaba. The theoretical backgrounds, challenges, experiences and best practices of asset management in the water sector, based on the five asset management questions that Waternet uses were shared with the participants. This was followed by a five-day in-depth technical asset management training in November 2017 at IHE-Delft, the Netherlands, for seven Jordanian "asset management ambassadors" from the three water utilities, the Ministry of Water and Irrigation, and UNICEF. A four-day workshop with the objective of developing a fit-for-purpose IAM plan for the Al-Mafraq water supply system, as a pilot case, was organized at Al-Mafraq in January 2018. There were about 20 participants from the Ministry, UNICEF, and the three water utilities previously identified as AM ambassadors. The asset management ambassadors played a crucial role as co-facilitators, for which they had been prepared by the earlier trainings. Half of the participants in this training were from Yarmouk water utility ranging from the level of the director to field engineers.

\subsection{Understanding the Jordanian Context}

Jordan's renewable water resources are limited and insufficient to meet the national demand [40]. Jordan's annual renewable resources are less than $100 \mathrm{~m}^{3}$ /capita for all purposes including irrigation, 
industrial and municipal, which is far below the global threshold of $500 \mathrm{~m}^{3}$ /capita indicating "severe water scarcity". Jordan's national water resources and water balance are negatively impacted due to higher demand, over-abstraction, and climate change [41]. The water sector in Jordan is characterized by severe water scarcity, increasing demand due to the severe influx of refugees, and economic development needs. Jordan is hosting about 1.3 million Syrians, of which 655,833 are registered as refugees with UNHCR in the northern governorates. The refugee influx resulted in the plummeting of the per capita share of water by $27 \%$ [42]. The northern governorates suffer from several issues such as increasing water demand, limited water resources, a small amount of water supply per capita, and high non-revenue water (NRW). This is apparent from the water vulnerability maps developed jointly by UNICEF and the Water Authority of Jordan (WAJ). The vulnerability indicators took into consideration factors such as population, number of refugees per governorate, number of water subscribers, planned water supply, average water consumption, available ground and surface water resources, etc.

Despite Jordan's severe water scarcity, more than $94 \%$ of Jordanians have access to safe drinking water and $93 \%$ have access to improved sanitation. These are some of the highest rates in the Middle East and Northern Africa (MENA) region. However, water supply is intermittent, over periods ranging from once per week to sometimes once per month in some economically backward and remote areas. Rooftop storage tanks are part of the water supply system to cater to water needs over the periods of non-supply. The water supply and wastewater treatment in Jordan are managed by the three Jordan water utilities, Yarmouk, Miyahuna, and Aqaba, each serving the respective territorial and neighbouring governorates, while the Water Authority of Jordan (WAJ) functions as an operator in some areas. The city of Mafraq which is located in Mafraq, a northern Governorate, is affected by a lack of water supply, service intermittency, and a massive increase in population due to hosting the largest refugee camp in Jordan-Zaatari Refugee Camp. The Yarmouk water company is responsible for managing both water supply and sewerage systems in Al-Mafraq. The gathering of information related to water and sewerage systems in Al-Mafraq pertaining to the five asset management questions was carried out by World Waternet (a division of Waternet responsible for international collaborations and capacity development), jointly with WAJ, UNICEF, and Jordanian water utility employees [16].

\subsection{Water Assets of Al-Mafraq}

The key in asset management is "knowing the assets you have"; hence, discussion among the January 2018 participants led to the drawing of a schematic of the current water supply system in Al-Mafraq (Figure 3), an essential first step. Furthermore, this also proved to be a useful exercise for sharing knowledge and improving mutual understanding of the water systems among different employees. The experienced employees of the water utility operator had a very good understanding of the part of the water supply system they were operating. However, discussions revealed that there is a lack of consensus on the actual functioning of the system as a whole, even at the level of highest abstraction. This is not unusual as, in many utilities, inadvertent compartmentalization of information and tacit knowledge is a regular phenomenon [43,44]. Nearly a full-day spread over the first two days was spent on arriving at accurate high-level schematics for the (a) water supply scheme and (b) distribution/rationing scheme. The process of developing a hydraulic model for the system was started but was dropped as (i) it was not a high priority in this context; (ii) there was a lack of consensus about the reality even at the abstract level; and (iii) water was rationed due to a severe lack of water, leading to constant flux in system operation. It is useful to have a good hydraulic model for a better understanding of system operation, but not critical at the very beginning of the process of implementing an IAM strategy. 


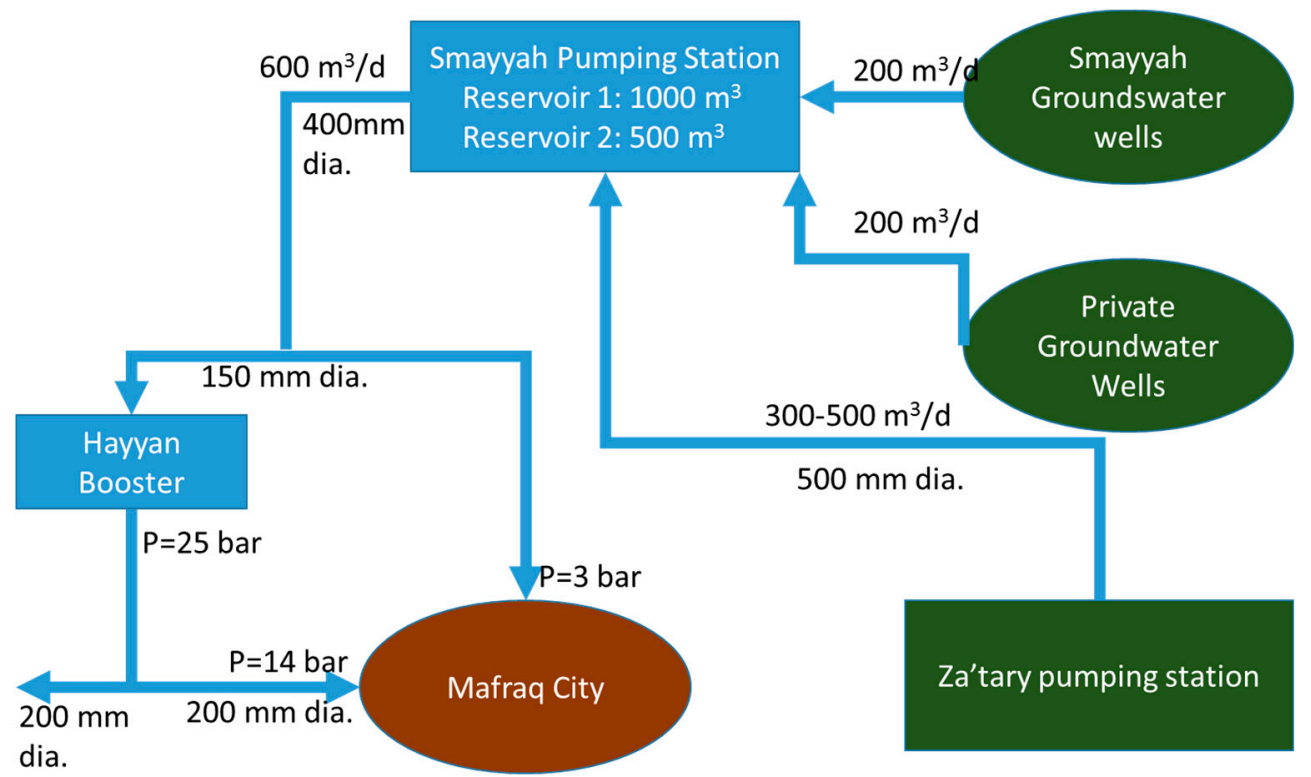

Figure 3. Water supply system for Al-Mafraq. This schematic diagram was developed during the training workshop by the employees who participated in the training.

Al-Mafraq entirely depends upon groundwater for its domestic and industrial water needs. Water is sourced from tube wells owned by Yarmouk water utility near Smayyah pumping station, Za'tary pumping station, and from private wells. Water from all these wells is collected at Smayyah pumping station and conveyed to Al-Mafraq through a 400-mm diameter transmission line. Al-Mafraq does not have an elevated service reservoir, and the distribution network is directly coupled with this transmission main. Hayyan booster pumping station within Al-Mafraq pumps water to the elevated areas. Al-Mafraq is divided into water rationing zones, a practice prevalent in Jordan as water is scarce. Each zone is supplied with a limited amount of water during a designated period of the week and is managed based on the knowledge of the operators. Due to the absence of detailed data and for the sake of simplicity, these rationing zones (which are practically district metering zones as they can be independently closed/opened) represented the distribution network within the city for our risk analysis instead of, for example, individual pipes. The schematic drawing (Figure 3) and understanding the daily water rationing practice helped in identifying and discussing the operational problems, as well as the critical assets. Field visits and consultations with the field staff enabled a comprehensive understanding of the water supply system and its operation. Also, it created an awareness of the importance of having an asset register with basic data including age, condition, and failure rates.

\subsection{Risk Mapping of Assets in Al-Mafraq}

The preparation of the schematic diagram, and the joint field visits and discussion about the assets led to the consolidation of information needed to answer the following: asset management questions such as (a) Which assets do we have and how are these assets performing?; (b) Which assets fail often, and why?; (c) Which assets are the most important?; This information was used to perform the risk analysis based on the probability of failure and consequence of failure resulting in the risk matrix for the Al-Mafraq water supply system (Figure 4). From Figure 4, it can be seen that the probability of failure and consequence of the failure of assets in Al-Mafraq's water supply system varies. The most critical assets - transmission main and Hayan booster - can be found at the top right corner of the matrix, which has the highest consequence of failure and the highest probability of failure. 


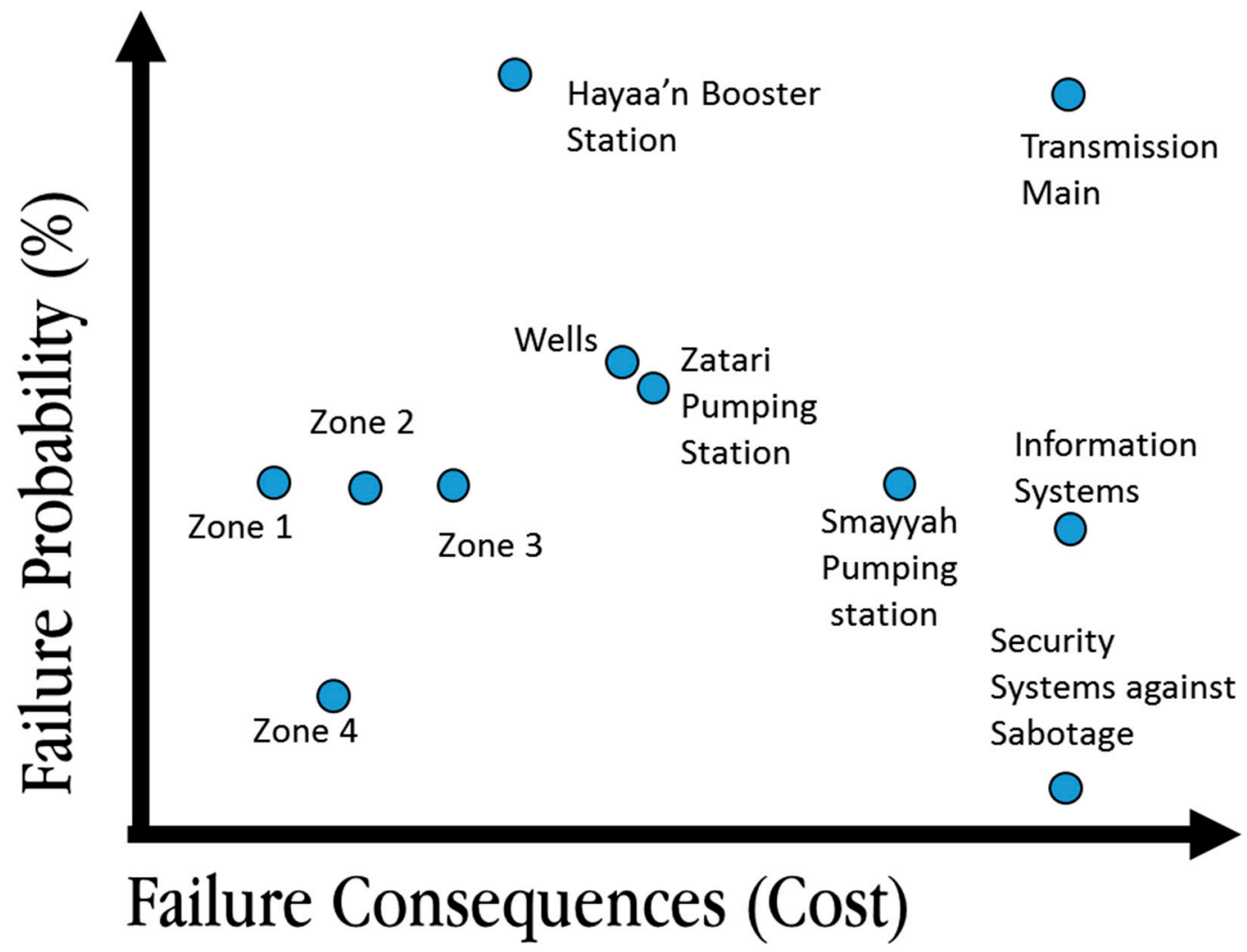

Figure 4. Risk matrix developed for the Al-Mafraq water supply system. Zone 1 ("Nowara" area), Zone 2 ("Hussain Feddin" area), Zone 3 (south areas), and Zone 4 ("Souq" area) are the four water rationing areas in the distribution system.

During the discussion to prioritize the assets based on the risk matrix, it was found out that there are other major concerns and constraints that have an influence on decision-making. Yarmouk water utility faces major constraints such as lack of funds, lack of water resources, lack of structured inventory of assets and stock registry, and lack of skilled staff and spare parts. These constraints are in addition to the increase in water demand to satisfy the needs of refugees and the inability to collect money for water supplied. Hence, the decisions regarding asset management in Ai-Mafraq have to consider the risk to the assets, as well as the current deficits and constraints in the systems that have to be prioritized to be addressed. This necessitates the broadening of the scope of IAM beyond the maintenance of the status quo.

\subsection{Risk and Constraint-Based Prioritization}

On the last day of the workshop, discussions were held to collate the actions to be taken to reduce the risks to the assets. The risk matrix and the deficits faced by the water system were discussed in detail, and a list of actions was prepared to reduce the risk under the constraining circumstances (Table 1). Also, the time taken to implement these actions and cost of these actions were worked out. The set of actions was prioritized based on the risk and deficits. Table 1 contains the prioritized actions ordered with priority decreasing from the top to the bottom. It is clear that there are actions which are not directly related to the risk of assets presented in the risk matrix (Figure 4), such as renewal of networks in villages around Smayyah pumping station and constructing an elevated storage reservoir. 
Table 1. Prioritized actions to reduce the risk of assets, as well as improve the current situation in Al-Mafra. Note that some of the actions do not arise from the risk matrix, but from another driver, i.e., current deficits in the system. JOD—Jordanian dinar; O\&M-operation and management.

\begin{tabular}{|c|c|c|c|c|}
\hline Action & Driver & Cost (Million JOD) & Time (Months) & Impact \\
\hline $\begin{array}{l}\text { Renew networks in villages } \\
\text { directly supplied by Smayyah } \\
\text { pumping station }\end{array}$ & Deficits & 3 to 4 & 12 to 36 & $\begin{array}{l}\text { More water for Al-Mafraq } \\
\text { Reduction in water theft } \\
\text { Less strain on O\&M crew }\end{array}$ \\
\hline $\begin{array}{l}\text { The transmission line from } \\
\text { Smayyah pumping station } \\
\text { (new line and old line } \\
\text { as standby) }\end{array}$ & Risk & 3 & 6 & $\begin{array}{l}\text { Reduction in risk to the system } \\
\text { Lower O\&M cost } \\
\text { Lower energy cost } \\
\text { Less loss of head }\end{array}$ \\
\hline $\begin{array}{l}\text { Change poor-quality valves in } \\
\text { Al-Mafraq and also install } \\
\text { valves that can be operated on } \\
\text { a daily basis to ration water }\end{array}$ & Risk & 0.07 & 12 & $\begin{array}{c}\text { Better rationing } \\
\text { Lower O\&M cost } \\
\text { Better pressure management }\end{array}$ \\
\hline $\begin{array}{l}\text { Creation of asset registry + } \\
\text { hydraulic model + asset } \\
\text { management unit }\end{array}$ & Deficits & 0.1 & 36 & $\begin{array}{l}\text { Avoid loss of information } \\
\text { Establishing clear procedure } \\
\text { Increase in } \\
\text { organizational efficiency }\end{array}$ \\
\hline Rehabilitating Hayyan booster & Risk & 0.5 & 6 & $\begin{array}{c}\text { Improving supply to Distribution } \\
\text { Management or District metered } \\
\text { Areas (DMAs) }\end{array}$ \\
\hline $\begin{array}{c}\text { Elevated service (storage) } \\
\text { reservoir } 800 \mathrm{~cm}^{3}+ \\
\text { improvements to the } \\
\text { distribution system } \\
\text { (KfW study) }\end{array}$ & Deficits & 10 & 24 & $\begin{array}{l}\text { Better O\&M } \\
\text { Decoupling pumps and } \\
\text { distribution system } \\
\text { Savings in energy }\end{array}$ \\
\hline $\begin{array}{l}\text { Rehabilitating four pumping } \\
\text { stations around Al-Mafraq }\end{array}$ & Risk & 0.5 & 12 & $\begin{array}{c}\text { Improved water supply in villages } \\
\text { Water savings } \\
\text { Lower O\&M cost } \\
\text { Savings in energy }\end{array}$ \\
\hline $\begin{array}{l}\text { Establishing a store to stock } \\
\text { the spare parts }\end{array}$ & Deficits & 2 & 6 & $\begin{array}{l}\text { Reduced downtime of assets } \\
\text { Improved service }\end{array}$ \\
\hline
\end{tabular}

\subsection{Evolution of Al-Mafraq-Specific IAM Framework}

At the end of the workshop, the trainers and the organizers of the workshop reviewed the sequence of actions which led to the risk matrix and prioritization of actions in Al-Mafraq. The IAM framework which evolved during the training workshop in Al-Mafraq is presented in Figure 5. The actions and the process during the workshop were compared with the IAM practices in Waternet (very similar to those explained in IAM literature), and a significant departure was noticed. 


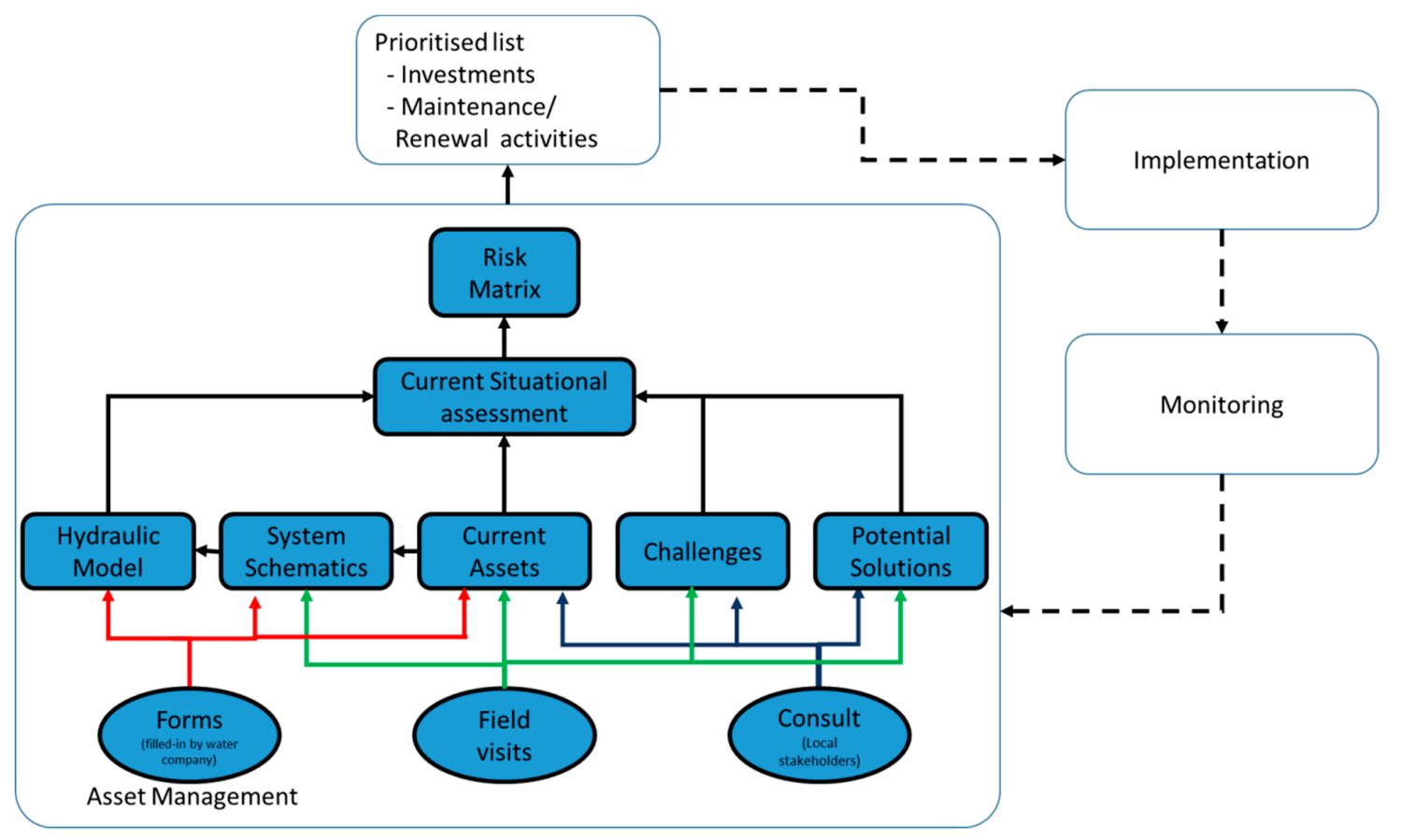

Figure 5. Contextualized IAM framework used for introducing the IAM process to Al-Mafraq.

\section{Findings and Observations from Al-Mafraq IAM Training}

The initial assignment was to come up with a risk matrix based on risk assessment for decision-making to facilitate asset management in Al-Mafraq and to identify the top-priority projects. The interactive workshop sessions not only imparted knowledge about asset management and risk assessment but also led to an increased understanding of the system functionality, i.e., understanding the system performance, understanding the capability and sustainability of the system. The asset management ambassadors who were already exposed to theoretical and practical aspects of IAM were instrumental in developing the IAM framework for Al-Mafraq. They also emphasized the need for and the usefulness of an improved system of inventory of available assets in a structured manner, which can be frequently updated.

\subsection{To Prioritize or Not to? Integrating the Priorities}

In most cases, it is imperative to prioritize the actions, as the focus is to effectively utilize the limited resources and to be efficient. In order to simplify the selection process, the prioritized actions (Table 1) could be evaluated against three criteria: "doability" (effort needed to implement), swiftness (time taken to implement), and effectiveness (how effective it achieves the system objectives). A diagram similar to Figure 6 can help illustrate this in a manner conducive for prioritization. 


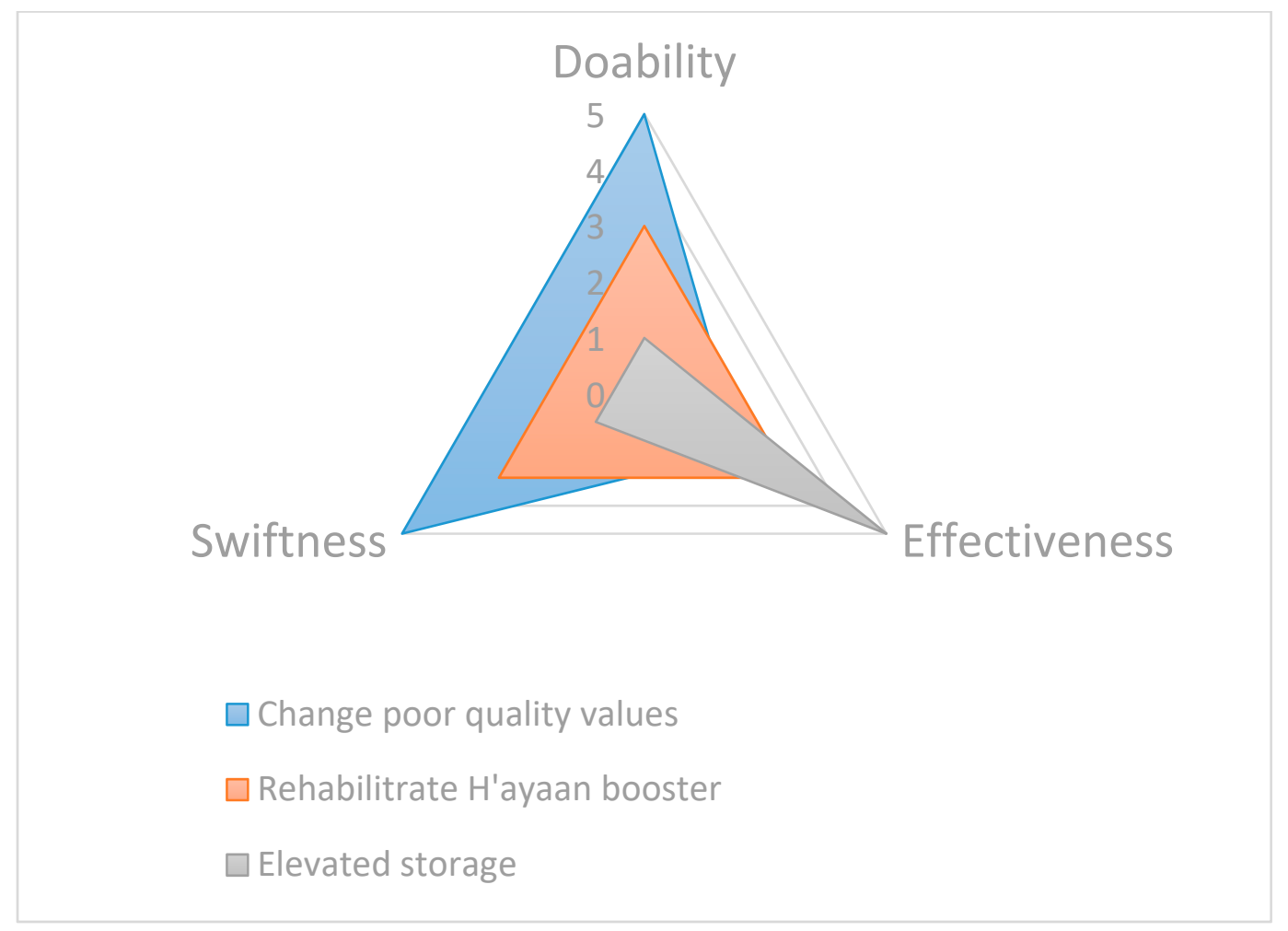

Figure 6. A multi-criteria approach to prioritize shortlisted interventions. Doability: effort needed to implement (in the present case, cost was used-higher cost = lower doability); effectiveness: how effective it achieves the system objectives; swiftness: time taken to implement (how fast it is implemented).

\subsection{Aliging Stakeholder Interests}

Al-Mafraq also faces a unique challenge. The financing of projects in Al-Mafraq is done by a myriad of sources that include national and international sources. There are a number of donors who pitch in with investments particularly owing to the refugee situation. While the Jordanian government (Ministry of Water and Irrigation) makes attempts to streamline and systematize these sources, it still remains complex and highly uncertain process. For example, Ministry of Water and Irrigation organize a bi-monthly donor meeting where project priorities and investment possibilities are discussed and coordinated among donors. As far as the point of view of the utility is concerned, there is no certainty as to which type of interventions will be funded and at what point in time. In this context, it makes sense to have the final shortlisted interventions (Table 1) as a sort of a "needs list" without any special priority among them. When donor opportunities arise, it is possible for the utility to suggest that the donor chooses from this needs list. By having a shortlisted set of interventions, the utility makes sure that the donors choose from a list that the utility created by following a logical methodology, rather than leaving it to be, at best, a last-minute idea or, at worst, one that the donor comes up with. Different donors come with different levels of funding and other requirements which also impact the choice. In this context of high uncertainty of funding, it is not very productive to have a strictly prioritized project sequence. Leaving some freedom to choose is a better option given the ground realities of financing. Hence, the goal of prioritization in contexts like Al-Mafraq should be to identify a preferred set of actions solidly based on local context.

Further building of an asset register, development of a hydraulic model for Al-Mafraq, and the installation of flow and pressure meters funded by UNICEF and Yarmouk can enhance the system understanding. This can lead to a validated hydraulic model, the establishment of water balance, and the quantification of actual non-revenue water. This enhanced system understanding will guide 
the water utility to revisit the introduced IAM process (Figure 5) routinely and revise and refine the priority list (Table 1). For example, better data and a hydraulic model can provide more objective information for identifying priority actions, which is currently done with a guided discussion using just the subjective knowledge of the water utility.

\section{Discussion}

The insights obtained from the application of the IAM framework to prioritize O\&M and investment actions in the water supply system of Al-Mafraq can be summarized in the form of an enhanced asset management framework suitable for cities like Al-Mafraq. The enhanced asset management framework can be applied in contexts where asset management should address (a) risk to the current SL, (b) significant improvements needed in the current SL and (c) uncertainty of external factors and growth leading to extreme difficulties in the assessment of future needs. Although this framework was developed with the current case study, it provides a way of applying IAM in secondary cities in the global south (SCGS) which are characterized by the aforementioned features.

\subsection{IAM Questions for Water Utilities Facing High Uncertainties}

Every IAM framework ventures forward with a set of questions, as discussed in the introduction. This exercise started with the premise that the current risk-based IAM frameworks need to be expanded to be useful for applications in Al-Mafraq. This was accomplished in two stages. Firstly, a curated list of questions was proposed that covers all the essential aspects of IAM in the traditional sense. Secondly, these questions were supplemented with new questions that are necessary for it to be useful in the context of rapidly changing cities like Al-Mafraq, where there is a need to improve service levels and to cater to the increase in demand in a resource-constrained environment [29].

In Table 2, column 2 is the list of proposed IAM questions, inspired by traditional IAM questions posed by asset managers [21]. The questions are split into two categories: questions pertaining to IAM (A1-A4) and those related to SP (S1 and S2). Table 2, column 3 lists extra questions that need to be asked when the application context is SCGS or similar environments (M1-M4; and P1 and P2). These questions can provide essential information in contexts where (a) there is a significant deficiency in current service levels in relation to established service level benchmarks (M1-M4), and (b) growth and change situations are so dynamic that it is practically impossible to agree on a single likely future (P1 and P2).

Table 2. An expanded framework for infrastructure asset management (IAM) comprising a reformulation of "traditional" asset management questions (Column 2) and additional questions to make IAM fit the purpose of applying to the context of secondary cities in the global south (SCGS) (Column 3). SL-service levels; SP-strategic planning.

\begin{tabular}{|c|c|c|}
\hline & Traditional IAM Context & Expanding to SCGS \\
\hline IAM questions & $\begin{array}{l}\text { Addressing current risk (A) } \\
\text { (A1) What do we have? (Asset registry) } \\
\text { (A2) In what condition are the assets? } \\
\text { (Condition assessment) } \\
\text { (A3) What is the consequence of the failure of } \\
\text { each asset? (critical assets) } \\
\text { (A4) How to prioritize actions? (risk matrix) }\end{array}$ & $\begin{array}{l}\text { Addressing current deficits (M) } \\
\text { (M1) What are the plausible actions for } \\
\text { addressing current deficits in the } \\
\text { system? (long list) } \\
\text { (M2) What will be the impact of those } \\
\text { actions on expected SL? } \\
\text { (M3) What are their implementation } \\
\text { efforts? (cost + other efforts) } \\
\text { (M4) How to prioritize actions? } \\
\text { (cost/benefit) }\end{array}$ \\
\hline SP questions & $\begin{array}{l}\text { Addressing "known" future (S) } \\
\text { (S1) What are the possible/probable future } \\
\text { pressures? (demand, supply, service levels) } \\
\text { (S2) What are the long-term plans? (financing, } \\
\text { supply changes, SL changes) }\end{array}$ & $\begin{array}{l}\text { Addressing unknowable future }(P) \\
\text { (P1) What are the plausible futures? } \\
\text { (scenarios) } \\
\text { (P2) What strategic action can be taken } \\
\text { to prepare for the uncertainty? }\end{array}$ \\
\hline
\end{tabular}




\subsubsection{How to Answer the New Questions?}

The "traditional" IAM and SP questions were answered by risk-based analyses cycles (asset inventory, condition assessment, failure-consequence analysis, and a risk matrix) and strategic planning exercises, respectively. Since new questions were defined (M1-M4 and P1-P2 series in Table 2), it is important to discuss how these questions might be addressed. Answering M1 involves extended discussions (brainstorming) within the different departments of the asset management organization (in the above case study, it was Yarmouk water utility), as well as engaging other stakeholders (e.g., higher levels like provincial and central governments, consumer organizations, and the donor community). The answers should cover (a) existing proposals for improvement that are both funded and yet to be funded, and (b) new ideas that the participants may come up with. At this stage, there is no need to limit AM actions based on any other criteria. The result of such a brainstorming exercise will be a long list of possible and/or necessary interventions. The traditional IAM questions (A1-A4) aim at prioritizing existing asset components for renewal/replacement (A4). This is achieved by following a risk-based approach, with inputs from A2 and A3. However, in the M series that is additionally needed for SCGS, it does not deal with existing assets, but rather, perceived actions. These, for example, can be based on cost-benefit analyses. Comprehensively addressing the issue of prioritizing actions in SCGS (M4) is an area that needs active research.

Based on the experiences in Al-Mafraq the following suggestions with regards to plausible actions addressing current deficits (M2) and the impact due to plausible actions (M3) were made. Regarding M2 (What will be the impact of each intervention in the long list in improving expected SL?), examples of suggestions include improving water rationing, reducing NRW, system downtime, etc. This also includes risk reduction, because the risk in IAM includes an expected (negative) impact on SL. In the case of Al-Mafraq, group discussions and consultations were used as inputs to assess the impact reduction. The stakeholders discussed the impact of each solution on SL and agreed on a rating. In the case of Al-Mafraq, the stakeholders were also asked to list possible positive impacts. M3 is about effort. While the cost of an intervention is an important aspect, there could be others, such as the technical complexity, and the motivation of stakeholders to implement the solution. However, in the case of Al-Mafraq, the discussion was limited to the cost. Also in the context of Al-Mafraq, the interventions are mostly donor-driven. Answers to M2 and M3 provide the basis for shortlisting interventions from the aforesaid long list. During the Al-Mafraq case, this shortlisting was done by asking the stakeholders to select interventions from the long list, paying attention to the answers of M2 and M3. This process follows the contours of a cost-benefit analysis, although it can probably benefit from a more explicit methodology based on better information. Once such a shortlist is available, it is necessary to integrate these interventions with those from the risk analysis (A1-A4).

\subsubsection{The Impossibility of Answering SP Questions and Consequences}

Eight asset management questions (A1-A4 and M1-M4 in Table 2) were identified to apply asset management in SCGS. How about the strategic planning questions? S1 and S2 are "traditional" strategic planning questions that are often attempted to be answered. However, here, the possibility of answering these questions with a degree of certainty is highly questionable in SCGS [45]. Future operating conditions and the state of these asset systems are often so uncertain that it does not make a lot of sense to answer these questions as probable futures. Does this mean that asset managers in SCGS should simply forget the medium- and long-term future? No, they should engage in exercises to explore scenarios or a number of plausible futures. Scenarios are not probable futures, but just set-ups picked up from a huge number of plausible states. Stakeholders should understand that these are used not to "predict" the future in any sense, but to open their minds to the immense range of possible future states, and to stimulate thinking on how to prepare for such states (P2). This encourages them to focus on how to make the system gradually better and to reduce the risk as much as possible, as opposed to keeping a single future vision in mind as the primary driving force. Ideally, they should look at possibilities on how to make the asset systems highly agile, so that they can respond well to a 
myriad of future situations. For example, there are plans which describe the various possible scenarios for Mafraq and Zaatari camp based on geopolitical stability and economic growth, such as developing the region into a manufacturing hub, agricultural area, or tourism area; or making the Zaatari camp temporary, permanent, or semi-permanent [46]. Strategic planning of Al-Mafraq should be based on these scenarios.

\subsection{Applicability of (Scope for) Fit-for-Purpose IAM Framework in the Global South}

With the insights gained from initiating IAM in the Yarmouk water utility, an enhanced IAM framework was developed that is suitable for utilities and other asset systems with significant deficits in current levels of service, for example, many utilities in SCGS. The case study of Al-Mafraq can be seen as unique due to the acute demands on the system due to the refugee context. The infrastructure lagging behind increasing demands is a creeping issue (gradually changing over time) in many SCGS and, therefore, often escapes the attention. The case of Al-Mafraq justifies the need to expand the IAM framework to suit the contexts where infrastructure service levels are lagging behind, a common feature of SCGS.

There are two types of asset management priorities for SCGS-those dealing with the threats to the current service levels (leading to risk-based analysis) and those striving to improve current service levels (as they are often far from satisfactory). This duality has clear parallels with the discussion on adaptation gaps (a likely reduction in service levels in the future to changes such as climate, social, and economic factors), and adaptation deficits (the current reduced service levels due to poor service provision and increase in demand) in the literature on climate adaptation $[29,45]$. The risk-based approach form maintaining the current service levels is similar to addressing adaptation gaps while improving service levels are parallel to addressing adaptation deficits. Risk-based decision-making, therefore, is a part of such a framework, but not the whole. IAM questions have to be augmented to address current deficits in service levels (Table 2). There are issues with the traditional strategic planning questions as well. While strategic planning questions are important, these contexts are beset with extreme levels of uncertainty and out of the control of water utilities, making the creation of static long-term plans, challenging.

There is a perennial debate on the validity, applicability, and utility of "western concepts", those from developed countries in the west, in the context of resource-deprived conditions of some developing countries. For example, there is a debate on optimizing the water distribution network based on reducing the formation of carcinogenic disinfection by-products due to chlorination $[47,48]$. Such a reduction in health risk is valid in a European, urban American, or Australian context where the water services are performing at optimal levels [49,50]. However, the need to reduce the concentration of carcinogenic disinfection by-products is not a priority in developing countries like India or Kenya where polluted sources, insufficient treatment capacity, and intermittent water supply are the biggest challenges to water quality [51-53]. It can be argued that infrastructure asset management is an exception to this perception. As IAM is a process developed to address systems in crisis and challenges the sustenance of levels of service, it can deal with resource-deprived situations, which is the reality in many SCGS $[25,39,54-56]$. However, for IAM to be truly useful in SCGS, the scope of IAM should be expanded to improve the service levels by addressing current deficits in addition to maintaining the status quo of service levels.

\section{Recommendations and Conclusions}

Traditionally, when initiating an IAM program for an asset system, the usual practice is to make an inventory of the assets and agree upon a schematic of the water supply system before starting the assessment or discussion of actual IAM. In contrast, it is recommended not to wait for consensus on the system structure, performance, etc., among all water utility professionals, not to mention all stakeholders. In utilities where there is no documentation of assets, a considerable amount of time has to be spent mapping these assets and arriving at the consensus; this is not time wasted. This was 
confirmed by our experience in developing IAM practices for Al-Mafraq. Development of a common understanding of the system proved to be one of the most important investments of time and effort.

Regarding the proposed fit-for-purpose IAM framework, there are areas that need to be actively investigated further in order to come up with better outcomes and processes. For example, there needs to be further study and contemplation on better ways of answering new IAM questions or even improved formulation of those questions by tagging them with sustainable development goals (SDGs) or with bottom-up stakeholder involvement process to increase the inclusivity of the actions. In the case of Al-Mafraq, the existing IAM practice was reorganized by means of adjusting the existing process and adapting the IAM process to Al-Mafraq's context. However, there is scope for action researchers through research and practice to transform IAM in similar contexts using visions, experiments, and inventions to co-create favourable outcomes with stakeholders [57].

This paper focused on developing a fit-for-purpose integrated asset management (IAM) framework that is suitable for situations where there are risks to assets, significant uncertainties, and resource deficits, and where improvements to the current service levels are needed. The contextualized fit-for-purpose IAM framework was developed by adapting an existing IAM framework to prioritize the list of actions based on a risk matrix and system deficits. The process of adapting the existing IAM framework evolved during the interaction of researchers and practitioners of water utilities. Analysis of the evolution of this fit-for-purpose IAM framework revealed that it can be useful for emerging cities, such as the secondary cities in the global south (SCGS), where there is a clear need for managing assets and for improving the existing service levels, in addition to managing the risks to the current service levels. In order to guide the reorganization of the IAM framework, questions were framed to include current deficits and future needs, in addition to the standard asset management questions. The fit-for-purpose IAM framework comprising asset management, adaptation deficit, and future needs can ensure the continuity of service levels in emerging cities when supported through expert inputs and stakeholder consultations.

Author Contributions: All authors participated in the trainings and workshops that stimulated the idea for this manuscript. Conceptualization: A.P.; Methodology: A.P., M.R., M.B. and E.V.; Case study specific information: S.M. and H.A.A.R.; Writing—original draft preparation: A.P. and M.R.; Review and editing: All authors; Writing Coordination: M.R.

Funding: This work is funded by multiple sources including UNICEF and the Dutch Government.

Acknowledgments: This paper is an outcome of the joint effort of the water utilities Yarmouk, Miyahuna, and Aqaba, the Hashemite Kingdom of Jordan's Ministry of Water and Irrigation, Project Management Unit of the Ministry, IHE-Delft Institute for Water Education, World Waternet Amsterdam, and UNICEF Jordan Office (JCO). World Waternet is working within the VNG-I LogoRep program funded by the Dutch Ministry of Foreign Affairs. IHE-Delft's contribution was supported by Directorate General for International Cooperation (DGIS) of the Foreign Ministry of Kingdom of the Netherlands under the framework of the DUPC2 program. We fondly acknowledge the contribution of all the asset management ambassadors of Jordan.

Conflicts of Interest: The authors declare no conflicts of interest.

\section{References}

1. Kanakoudis, V.K.; Tolikas, D.K. The role of leaks and breaks in water networks: Technical and economical solutions. J. Water Supply Res. Technol.-Aqua 2001, 50, 301-311. [CrossRef]

2. Kanakoudis, V.K.; Tolikas, D.K. Assessing the Performance Level of a Water System. Water Air Soil Pollut. Focus 2004, 4, 307-318. [CrossRef]

3. Kanakoudis, V.K. Vulnerability based management of water resources systems. J. Hydroinform. 2004, 6, 133-156. [CrossRef]

4. Tsitsifli, S.; Kanakoudis, V. Predicting the behavior of a pipe network using the "critical Z-score" as its performance indicator. Desalination 2010, 250, 258-265. [CrossRef]

5. Kanakoudis, V.; Tsitsifli, S. Water pipe network reliability assessment using the DAC method. Desalin. Water Treat. 2011, 33, 97-106. [CrossRef]

6. Miller, K. Piper Alpha and The Cullen Report. Ind. Law J. 1991, 20, 176-187. [CrossRef] 
7. National Council on Public Works, I. Fragile Foundations: A Report on America's Public Works: Final Report to the President and the Congress; The Council for sale by the Supt. of Docs. Xiv; U.S. Government Publishing Office: Washington, DC, USA, 1988; 226p.

8. Infrastructure Australia. Australian Infrastructure Audit: Our Infrastucture Challenges; Report; Infrastructure Australia: Canberra, Australia, 2015.

9. Local Government New Zealand (LGNZ). Improving New Zealand's Water, Wastewater and Stormwater Sector in Position Paper; LGNZ: Wellington, New Zealand, 2015.

10. International Organization for Standardization. ISO 55000:2014 Asset Management-Overview, Principles and Terminology; International Organization for Standardization: Geneva, Switzerland, 2014.

11. Halfawy, M.R. Integration of municipal infrastructure asset management processes: Challenges and solutions. J. Comput. Civ. Eng. 2008, 22, 216-229. [CrossRef]

12. Meyer, M.; Amekudzi, A.; O'Har, J. Transportation asset management systems and climate change: Adaptive systems management approach. Transp. Res. Rec. J. Transp. Res. Board 2010, 2160, 12-20. [CrossRef]

13. Alegre, H.; Coelho, S.T.; Covas, D.I.C.; Almeida, M.d.C.; Cardoso, A. A utility-tailored methodology for integrated asset management of urban water infrastructure. Water Sci. Technol. Water Supply 2013, 13, 1444-1451. [CrossRef]

14. Large, A.; le Gat, Y.; Elachachi, S.M.; Renaud, E. Decision support tools: Review of risk models in drinking water network asset management. In Proceedings of the 2nd International Conference on Vulnerability and Risk Analysis and Management (ICVRAM) and 6th International Symposium on Uncertainty Modelling and Analysis (ISUMA), Liverpool, UK, 13-16 July 2014.

15. Halfawy, M.M.; Newton, L.A.; Vanier, D.J. Review of commercial municipal infrastructure asset management systems. J. Inf. Technol. Constr. 2006, 11, 211-224.

16. Bevaart, M.; van Heck, G.J. Water Assessments Mafraq City, Jordan; Waternet: Amsterdam, The Netherlands, 2017.

17. USEPA. Asset Management: A Best Practices Guide; USEPA: Washington, DC, USA, 2008; p. 4.

18. Institute of Public Works Engineering Australia. International Infrastructure Management Manual; Association of Local Government Engineers of New Zealand: Auckland, New Zealand; National Asset Management Steering Group \& Institute of Public Works Engineering Australia: Sydney, Australia, 2006.

19. Pathirana, A. Introduction to Asset Management. In Asset Management Module; Pathirana, A., Ed.; IHE Delft Institute for Water Education: Delft, The Netherlands, 2006.

20. USEPA. Strategic Planning Small Water Systems One of The Simple Tools for Effective Performance (STEP) Guide Series; USEPA: Washington, DC, USA, 2003; p. 29.

21. Waternet. Waternet Asset Management Approach, 3 Levels, 5 Questions in Strategie Assetmanagement Afvalwater Drinkwater (SAMP); Waternet: Amsterdam, The Netherlands, 2018.

22. Kanakoudis, V.; Cerk, M.; Banovec, P.; Tsitsifli, S.; Samaras, P.; Zouboulis, A. Developing a DSS tool to merge the gap between a water pipe network's NRW level assessment and the prioritization of the potential helaing measures. In Proceedings of the IPWE 2013 6th International Perspective on Water Resources \& the Environment, At Izmir, Turkey, 7-9 January 2013.

23. Kanakoudis, V.; Tsitsifli, S.; Zouboulis, A.I. WATERLOSS project: Developing from theory to practice an integrated approach towards NRW reduction in urban water systems. Desalin. Water Treat. 2015, 54, 2147-2157. [CrossRef]

24. Kanakoudis, V.; Tsitsifli, S.; Cerk, M.; Banovec, P.; Samaras, P.; Zouboulis, A.I. Basic Principles of a DSS Tool Developed to Prioritize NRW Reduction Measures in Water Pipe Networks. Water Qual. Expos. Health 2015, 7, 39-51. [CrossRef]

25. Vanier, D.D. Why industry needs asset management tools. J. Comput. Civ. Eng. 2001, 15, 35-43. [CrossRef]

26. Wenzler, I. Development of an asset management strategy for a network utility company: Lessons from a dynamic business simulation approach. Simul. Gaming 2005, 36, 75-90. [CrossRef]

27. Wijnia, Y.; Herder, P. The State of Asset Management in the Netherlands, in Engineering Asset Lifecycle Management; Springer: Berlin, Germany, 2010; pp. 164-172.

28. van der Velde, J.; Klatter, L.; Bakker, J. A holistic approach to asset management in the Netherlands. Struct. Infrastruct. Eng. 2013, 9, 340-348. [CrossRef]

29. Pathirana, A.; Radhakrishnan, M.; Quan, N.H.; Zevenbergen, C. Managing urban water systems with significant adaptation deficits-Unified framework for secondary cities: Part I—conceptual framework. Clim. Chang. 2018, 149, 43-56. [CrossRef] 
30. van der Helm, A.W.C.; Bhai, A.; Coloni, F.; Koning, W.J.G.; de Bakker, P.T. Developing water and sanitation services in refugee settings from emergency to sustainability-The case of Zaatari Camp in Jordan. J. Water Sanit. Hygiene Dev. 2017, 7, 521-527. [CrossRef]

31. Unicef and Reach. WASH Infrastructure E Services Assessment in Zaatari Camp; REACH Amman: Amman, Jordan, 2017.

32. Saidan, M.N.; Drais, A.A.; Al-Manaseer, E. Solid waste composition analysis and recycling evaluation: Zaatari Syrian Refugees Camp, Jordan. Waste Manag. 2017, 61, 58-66. [CrossRef]

33. Heywood, G.M.; Lumbers, J.P.; Starr, M. Capital Maintenance Planning Common Framework: Review of Current Practice; UK Water Industry Research Limited: London, UK, 2006.

34. Garvey, P.R.; Lansdowne, Z.F. Risk matrix: An approach for identifying, assessing, and ranking program risks. Air Force J. Logist. 1998, 22, 18-21.

35. Waternet. Risicomatrices Drinking Water (DW). In Waternet Risk Matix; Waternet: Amsterdam, The Netherlands, 2014.

36. Anthony Cox, L. What's Wrong with Risk Matrices? Risk Anal. 2008, 28, 497-512. [CrossRef]

37. Talbot, J. What's Right with Risk Matrices; Andy Lidstone: Warrington, UK, 2011.

38. USEPA. User's Guide: CUPSS—Check up Program for Small Systems; United States Environmental Protection Agency: Washington, DC, USA, 2014; p. 180.

39. Moglia, M.; Burn, S.; Meddings, S. Decision support system for water pipeline renewal prioritisation. J. Inf. Technol. Constr. 2006, 11, 237-256.

40. Al-Weshah, R.A.-M. Jordan's water resources: Technical perspective. Water Int. 1992, 17, 124-132. [CrossRef]

41. Ministry of Waste and Irrigation. National Water Strategy of Jordan, 2016-2025; Ministry of Water and Irrigation, Hashemite Kingdom of Jordan: Amman, Jordan, 2016.

42. Ministry of Planning and International Cooperation. Jordan Response Plan 2017-2019; Ministry of Planning and International Cooperation, Hashemite Kingdom of Jordan: Amman, Jordan, 2016.

43. Ann, R.R.; David, S. Facilitating tacit knowledge transfer: Routine compatibility, trustworthiness, and integration in M \& As. J. Knowl. Manag. 2015, 19, 257-276.

44. Grant, R.M. Toward a knowledge-based theory of the firm. Strateg. Manag. J. 1996, 17, 109-122. [CrossRef]

45. Pathirana, A.; Radhakrishnan, M.; Ashley, R.; Quan, N.H.; Zevenbergen, C. Managing urban water systems with significant adaptation deficits-Unified framework for secondary cities: Part II—The practice. Clim. Chang. 2018, 149, 57-74. [CrossRef]

46. Rutgers, V. Developing Zaatari-Urban Planning in a Syrian Refugee Camp, Jordan; VNG and City of Amsterdam: Amsterdam, The Netherlands, 2016.

47. Krasner, S.W.; Westerhoff, P.; Chen, B.; Rittmann, B.E.; Amy, G. Occurrence of disinfection byproducts in United States wastewater treatment plant effluents. Environ. Sci. Technol. 2009, 43, 8320-8325. [CrossRef]

48. Radhakrishnan, M.; Pathirana, A.; Ghebremichael, K.; Amy, G. Modelling formation of disinfection by-products in water distribution: Optimisation using a multi-objective evolutionary algorithm. J. Water Supply Res. Technol.-Aqua 2012, 61, 176-188. [CrossRef]

49. Zschille, M.; Walter, M. The Performance of German Water Utilities: A (Semi)-Parametric Analysis. Appl. Econ. 2012, 44, 3749-3764. [CrossRef]

50. Lannier, A.L.; Porcher, S. Efficiency in the public and private French water utilities: Prospects for benchmarking. Appl. Econ. 2014, 46, 556-572. [CrossRef]

51. Shah, T.; Van Koppen, B. Is India ripe for integrated water resources management? Fitting water policy to national development context. Econ. Political Wkly. 2006, 41, 3413-3421.

52. Kumpel, E.; Nelson, K.L. Intermittent Water Supply: Prevalence, Practice, and Microbial Water Quality. Environ. Sci. Technol. 2016, 50, 542-553. [CrossRef]

53. Ercumen, A.; Arnold, B.F.; Kumpel, E.; Burt, Z.; Ray, I.; Nelson, K.; Colford, J.M., Jr. Upgrading a Piped Water Supply from Intermittent to Continuous Delivery and Association with Waterborne Illness: A Matched Cohort Study in Urban India. PLOS Med. 2015, 12, e1001892. [CrossRef]

54. Rajani, B.; Kleiner, Y. Comprehensive review of structural deterioration of water mains: Physically based models. Urban Water 2001, 3, 151-164. [CrossRef]

55. Skipworth, P.J. Whole Life Costing for Water Distribution Network Management; Thomas Telford: Westerkirk, UK, 2002. 
56. Walski, T.M.; Haestad, I. Methods, Advanced water Distribution Modeling and Management; Haestead Press: Waterbury, CT, USA, 2003.

57. Fazey, I.; Schäpke, N.; Caniglia, G.; Patterson, J.; Hultman, J.; Van Mierlo, B.; Säwe, F.; Wiek, A.; Wittmayer, J.; Aldunce, P.; et al. Ten essentials for action-oriented and second order energy transitions, transformations and climate change research. Energy Res. Soc. Sci. 2018, 40, 54-70. [CrossRef] 